\title{
Essentials in the Training of University Librarians-IV
}

Robert Kerner is professor of modern European history, University of California.

$\mathrm{I}^{\mathrm{N}}$

A SENSE the position of university librarian has become an impossible one. It is expected that a university librarian should be an expert technical librarian, a splendid administrator, a first-rate public relations man, a scholar whose learning and insight should be the equivalent of a doctorate in a hundred-odd departments, and a human being besides. Stated this way, we know we are discussing a man that did not, does not, and never will exist. He is like the "economic man" our economists set up and tear down from time to time. If he lives, he lives in the imagination or the hazy and mystical future.

It is assumed, therefore, that we are not discussing such a fiction or even such a "library man" to shoot at. What we are discussing is a man who is to serve most usefully university scholars and students in a learned atmosphere.

Starting from this point, we may note that technical library school training is valuable, but not the most important item in his training. Help for that purpose should be readily available in his staff. In fact, it is easy to imagine a first-rate university librarian without this training. More essential is intensive study in some one broad field of knowledge, most probably the equivalent of the work for the
Doctor's degree. To obtain a doctorate would be most desirable. Its purpose is an intimate acquaintance with the problems which scholars and competent students meet in pursuing their work. These problems, if understood by the librarian, will be found to be more than simple bibliography, or a net-work of bibliographical tools capable of catching items which uncover materials and roads to knowledge. It will include some comprehension of the sources of that field and the numerous directions in which they lead, as well as the reverse. Once this training has been secured, it will react on all his judgments and relations. It will teach him fundamentals, obtainable in no other way. Having had this academic training, but necessarily lacking similar information and training in the hundred other fields of knowledge, such a librarian should be able to consult those who know, to pursue patiently and intelligently the purpose of building collections and of finding numerous other ways of serving scholarship. Such men will necessarily have some facility in the reading of French and German, if not also other languages.

\section{Should Engage in Productive Scholarship}

Such a librarian should engage to a limited extent in productive scholarship in his field of specialty, whether this be in the production of bibliographies which will be pioneers in forgotten or unknown direc- 
tions, or whether in the writing of monographs. Just as no real teacher can keep alive only by teaching, so the real librarian cannot be most useful without producing scholarly material. The teaching of a regular course in his special field might lead him to understand other problems. In fact, it would be more logical from this angle to select university librarians from among those scholars on the faculty who have already shown their skill as teachers and writers rather than from technically trained librarians. They can acquire what they need of that in a relatively short time.

Now, if to this we add a modicum of administrative and executive ability based on common sense, a certain tact in dealing with scholars and advanced students, and a little humor, we shall approach the ideal of a university librarian. Such a man would be welcomed in the society of schol- ars, in faculties, and by serious students. By his own training and judgment he would justify his place in the university community and in the national academic organizations. A university librarian, as such or as an individual scholar, could meet with the national academic organizations, thus gaining a comprehension of ideals and needs which he cannot get in any other way. He would cease to be merely a "clerk," or a "martinet," or a "hod-carrier," or "an obstacle to scholars and scholarship," terms so often heard in academic criticism. He would have a solid and respectable partnership in the business of academic life and he would disappear as a "problem" in nearly every university faculty. Such a librarian is a human possibility and it is possible to train such librarians. In fact, they are now being trained.

\section{Discussion}

Nathan van Patten, director of libraries, Stanford University, discussing Dr. Kerner's paper observed:

After reading Professor Kerner's paper I find myself in complete agreement with the views which he has expressed.

I came to the same conclusions as long ago as the New Haven conference and have continued to restate my belief that librarianship as a profession lacks a well defined content in the sense that law, medicine, and engineering have such a content.

The professional status of the librarian more closely resembles that of the college or university president. There is no professional school for the training of college and university presidents. The office has been filled with distinction and with failure by men who have come to it from the professions of law, medicine, theology, and engineering; from the army, from business, and from many subject specialties in teaching and research.

It seems clear to me that it is much better to attempt to make a librarian from a man or woman who is already well established in the practice of one of the older recognized professions than it is to expect young men and women with the limited training available in our library schools to become competent librarians under the continuing handicap of a lack of adequate preparation and a too frequent inability to orientate themselves in the society of scholars.

We should not overlook the fact that the formal training of the average library worker has covered from eight to eighteen months as compared with a minimum of sixty months in the case of the medical 
profession and that this sixty months is based upon a carefully planned pre-medical education of at least thirty-six months.

It is becoming increasingly apparent that we must either adopt an advanced concept as to what constitutes an adequate preparation for librarianship or be content to see the more important professional posts go to scholars who can bring to the office an experience and competency not easily found among those candidates who have been trained only in the technical aspects of librarianship. These candidates have as an advantage only the slender margin of from eight to eighteen months of formal instruction in the library school, a considerable part of which time has been given over to work which is certainly not upon a professional level.

Librarianship cannot gain recognition as a profession by continued assertion and protest. Professional status can be acquired by accomplishment, and accomplishment in librarianship is not a matter of improving technical processes, collecting statistics, and worrying too much in public about salaries and prestige.

Carl M. White, librarian, University of North Carolina, commented at the end of the foregoing discussion:

The PAPERS read today are dissimilar in some respects, but I am impressed by their similarities and it is these similarities I prefer to emphasize. In particular, I should like to emphasize the following points.

Everyone seems to agree, in the first place, that, as universities have grown, unusual demands have come to rest on the shoulders of the university librarian. Both the Wilson and the Kerner papers stress this point.
We seem to be agreed, in the second place, that these demands are not entirely uniform in all universities; that certain qualifications will inevitably weigh more heavily in certain appointments than in others; that, within limits, the resultant multiplicity and variety of gifts and points of view are valuable to the profession; that in practice, there seems to be no straight and narrow way leading directly from the cradle to a position as university librarian; and that it is therefore exceedingly difficult -impossible, in fact-to outline in detail a program of training which is universally and necessarily the best for all prospective university librarians.

Nevertheless-and here again we are agreed-training for university librarianship should be as systematic as we can make it, instead of being left to the accident of circumstances. It is undoubtedly true that the university librarian must bring to his task certain assets which, so far as I am aware, are never the direct product of class assignments and apprenticeship at regular desks of duty. But recognition of this fact is, I assume, not tantamount to saying that successful university librarians are born, not made. They are made in part by the background of training and experience which they bring with them to their daily decisions. The more we know, therefore, of the typical situations encountered during the career of the university librarian and plan programs of study with these realities in mind, the more we facilitate intelligent preparation for university librarianship. This is but applying a well-known principle of vocational training to our own profession, but it is a principle which has not claimed much attention until recently. Appropriating one of Wordsworth's figures, the university librarian has often 
found himself voyaging through strange seas of thought alone, without even a very deserving body of professional literature to guide him.

\section{University Aims Should Prescribe Service}

Agreement seems to extend even to the broad objectives of training. The university library exists, of course, to serve the university. Accordingly, the service given should be prescribed, not by some preconceived notion as to what library service is, but by the aims and policies of the institution to be served. The librarian who builds his program according to these specifications needs "a broad general understanding of the objectives of the university as a whole as opposed to a narrower departmental view; he should possess a scholarly knowledge of library science and related fields of scholarship; he should have a thorough understanding of the functional relationships which exist among the various departments of the library, and ability to organize and direct library personnel."

I have quoted the language of the Wilson paper. The other contributors might have said it a little differently but the exact phrasing does not matter. What is more important is that the functional conception of the university library which underlies the Wilson statement seems to be common to all of the views here presented.

Up to a certain point, the training programs recommended for attaining these objectives are themselves similar. Thus professional training should be postponed until the student has secured a sound general education and acquired familiarity with such tool subjects as he expects later to use.

When it is begun, professional training should embrace a year of concentrated study aimed at familiarizing the student with libraries considered as bibliographical and educational instruments. As I understand it, this is what library schools the country over are trying to do, each in its own way, through the curriculum for the first year.

Beyond a certain point, however, the training programs differ. The Kerner paper envisages a type of training which sees the librarian as a scholar in a community of scholars; the Williamson paper a type of training which sees the librarian at the head of a staff specially trained for the varied tasks performed in a modern research library; the Wilson paper a type of training which sees the librarian as an educational administrator; the Mitchell paper a type of training which sees the librarian as an inevitable combination of technician and scholar faced-at least at present-by embarrassing difficulties in getting in the time at his command the training he actually needs.

\section{Points of View Complementary}

While the views represented by the four papers are thus divergent, they are not disparate. In other words, so long as we keep to the positive emphasis in each paper, I see no inherent conflict. Instead, I find some justification for regarding the different points of view as complementary. Scholarly training, for example, has its place. How essential it is those of us who have been denied it can easily fail to appreciate. We are apt to know not and know not that we know not. University librarianship is, after all, a learned profession. Membership in the society of the learned is reserved for those having certain tastes and attainments which, without attempting accurate description, may be suggested by saying that they are the quali- 
fications sought in developing university faculties. Whatever else the university librarian must have in the way of equipment, it seems as though he should have the same kind of timbre and training his colleagues have. With Professor Kerner and some of Director Mitchell's respondents, I am personally unable to see any substitute for intensive study in some broad field of learning. Precisely what subjects qualify as legitimate "fields" is a difficult question but one which-I think it may be fair to say-is usually secondary to the manner of study and the attitude of the student. I find a little disappointing the suggestion that the degree of Doctor of Philosophy be regarded-like neon in a vacuum-as all but worthless in itself but as valuable for publicity purposes. The embryonic "climber" in the profession may as well be reminded before paying the price for his Ph.D. that degrees in themselves do not make a very salutary lasting impression on the learned.

\section{In Fairness to the Work}

Likewise library-school training has its place. How essential it is those of us who have been denied it can likewise easily fail to appreciate. Again we are apt to know not and know not that we know not. The library school works no miracle in its matriculants. It imparts no advices which are mysterious or inscrutable. Nevertheless, the library administrator cannoteven if he wished-confine himself to policies in the abstract and leave all operations in the concrete to "technicians." His decisions affect those operations all the way from the basement to the attic. In all fairness to the work and those who do it, therefore, universities need library administrators who are able to see the bibliographical and educational techniques in- volved in the best library service in clear perspective. Normally, the path to such understanding leads through the operations themselves, not around them. The necessary background may be secured through years of practical experience or a relatively few months of systematic study at a good library school. Many distinguished university librarians have had no formal library training, but probably very few of them would advise the longer route if the more systematic approach were available to the one being advised.

Finally, training aimed at broad educational and social perspective has its place. In fact, the end and aim of all training, academic or technical, might be said to be a species of educational statesmanship. Pick out a young scholar trained in English or some other subject, give him the usual nine months of training in a library school, place him in charge of a university library and his performance may be expected to remain below the level of that of the best university librarians for a varying period of years. What is the difference? Genius? Perhaps, but the successful librarian is more likely to attribute it to what he has learned during his experience. Some things are perhaps learned through experience and experience alone. Nevertheless, the principle still holds: Wherever an area of professional experience can be marked out and studied systematically, the learning period can be shortened. In the case of Professor Kerner's "library man," it ought to be possible to shorten the training period even further by bringing scholarly and professional interests into sharp focus during the period of graduate study. Undoubtedly there are problems to be worked out in developing a training program of this sort, but the idea of concentrating systematic study on 
what experience shows to be relevant to professional success seems to be sound.

In closing, I should like to turn the discussion in a slightly different direction.

So far, we have been dealing almost exclusively with the university librarian considered as the ranking member of the staff. What about the rest of the staff and the relation of their positions to his? Are we to think of the highest positions in the profession as within or outside the reach of the person who comes up from the ranks? My comments on these interlocking questions will necessarily be brief and will do little more than punctuate the Williamson paper with an emphasis to which it seems to be entitled.

Rephrasing one of the premises of that paper, a basic obligation of a profession is to provide continuity from the lower to the higher brackets of responsibility. The end in view, of course, is not to place a premium on mediocrity or seniority, but to allow the best ability to make its way to the top. There is a second value. One college of education refuses to announce courses for prospective deans of womenalthough it places young women in such positions regularly-on the ground that the self-picked dean of women is seldom as successful in every way as the one "discovered" and encouraged to enter the field by some educational administrator. A scheme of organization which permits young librarians with administrative ability to move from lower through higher to the highest positions enables the profession to pick and train its own future leaders better than a scheme which requires importing persons with ready-made training to fill the positions at the top.

By way of summarizing what needs to be done, the obvious place to begin is with recruiting. However, the new wine of ability which is sought will have to be handled with care. Existing forms of organization have left few positions below the top rung in the ladder which appeal to those whose interest and training equip them to do something besides routine work. I venture to say that this fact has had fully as much to do with discouraging persons of outstanding ability from entering the library field as salaries-although we have heard considerably more of the latter. The new plan of staff organization put into effect recently at the University of California affords one type of solution to this problem. Its success will be watched carefully by other university libraries.

Finally, training needs to be considered as a phase of good library management. Industry has learned the lesson already. Key positions are filled by persons who have, besides their formal training, a certain amount of training on the job. It is taken for granted that no school and no chance moving from one industrial center to another will provide the type of selection and training needed. Different libraries have differing practices, but the tendency is to regard training as essentially the function of the library schools. Whether in-service training is to include systematic study during the period of employment is a mater of terminology, but there is no doubt as to the responsibility of the university and the university librarian for both. The illusion that the only way to grow professionally is to get away from work and study for a degree needs to be shattered. Nevertheless, those who really deserve encouragement to go further-either in academic or more narrowly technical studies-should receive it. 